\title{
LA REPRESENTACIÓN DE GOG Y MAGOG Y LA IMAGEN DEL ANTICRISTO EN LAS CARTAS NÁUTICAS BAJOMEDIEVALES
}

\author{
POR \\ SANDRA SÁENZ-LÓPEZ PÉREZ \\ Universidad Complutense de Madrid
}

\begin{abstract}
La leyenda del encierro de Gog y Magog por Alejandro Magno gozó de gran repercusión en la Edad Media, formando parte de las concepciones geográficas de este momento, y materializándose en la cartografía. Fruto de los cambios que experimenta a lo largo de los siglos, el Anticristo pasa a formar parte de la misma. Este artículo analiza una de las imágenes del Atlas Catalán de problemática interpretación: la imagen del Anticristo como falso profeta realizando milagros, para algunos hasta ahora, la ilustración de Dios en el Paraíso. Dicha ilustración perdura dentro de la Escuela de Cartografía Mallorquina en obras vinculadas al mismo taller o corriente artística. Dentro de la influencia que ejercen las cartas mallorquinas sobre la Escuela de Cartografía Sevillana destaca la persistencia de esta representación en la carta de Juan de la Cosa.

Palabras clave: Anticristo; Falso Profeta; Gog y Magog; Atlas Catalán; Escuela de Cartografía Mallorquina; Carta de Juan de la Cosa; Jean de Mandeville; Apocalipsis Anglo-Normandos; Hortus Deliciarum; Herrad de Hohenberg.

The legend of the enclosure of Gog and Magog by Alexander the Great had important repercussions during the Middle Ages. It constituted part of the geographical concepts of the period and was materialized in cartography. Due to the evolution that the legend underwent over the centuries, the Antichrist came to form part of it. In this article the author analyzes one of the problematic images from the Catalan Atlas, until now considered by some scholars to be a representation of God in Paradise. Here it is interpreted as being the Antichrist as false prophet performing miracles. This image endured for a long time within the Mallorcan School of Cartography in works associated with the same workshop and area of influence. A result of the influence of the Mallorcan charts on the Sevillian School of Cartography is the presence of this image in the Chart of Juan de la Cosa.

Key words: Antichrist; False Prophet; Gog and Magog; Catalan Atlas; Mallorcan School of Cartography; Chart of Juan de la Cosa; Jean de Mandeville; Anglo-Norman Apocalypse; Hortus Deliciarum; Herrad de Hohenberg.

El Atlas Catalán ${ }^{1}$ es sin duda uno de los mapas medievales que más ha llamado la atención a los investigadores, y aunque sobre el mismo ya existen muy interesantes publicaciones, aún faltan por identificar algunas representaciones y leyendas a través de las cuales Cresques Abraham, cartógrafo al que se atribuye esta obra, desvela la imagen y el conocimiento del mundo en 1375 , fecha en la que se asume fue realizada.
\end{abstract}

${ }^{1}$ Bibliothèque nationale de France, Paris (Francia), Ms. Espagnol 30. 
En el extremo Nororiental del continente asiático, lindando con el «Mare Oceanum» y sobre la región de «Catayo» (China), bajo dominio de «Holubeim» (Kublai Khan), se representan «los monts de Caspis» (los montes del Caspio) a modo de cordillera continua y cerrada sobre si misma que cerca un espacio, a su vez dividido por otro tramo montañoso. Tras estos montes se desarrolla una de las leyendas de mayor repercusión en la Edad Media: el encierro de Gog y Magog por Alejandro Magno detrás de los montes del Caspio. Violentos y destructores, según las profecías ${ }^{2}$ saldrían de su aislamiento en tiempos del Anticristo para invadir y asolar la cristiandad, antes de su definitiva destrucción ${ }^{3}$. Cresques Abraham, a través de un texto explicativo que acompaña la representación del Atlas Catalán, narra la leyenda de la siguiente manera: «Muntanyes de Caspis dins les quals Allexandri viu arbres ten alts que les saines tochaven a les nuus e aquí cuidà morir, sinó que Setanat l'en gità per la sua art a per la sua art endoý aquí los tartres Gog e Magog e per éls féu les ·II - images de matall, los demunt scrits. Ítem encloy aquí molts diverses generacions de gens qui no dupten a manjar tota carn crua, e aquesta és la generació ab què vendrà Antichrist e la lur fi serà foc qui avalar[à] del cel qui.ls confondrà» ${ }^{4}$.

Tal como se menciona en el Atlas Catalán, a finales de la Edad Media Gog y Magog fueron identificados con los mongoles, comúnmente denominados tártaros, según A. R. Anderson por influencia de los geógrafos musulmanes ${ }^{5}$. Esto no es de extrañar ya que en el siglo xiII, la cristiandad entera temía la invasión de este pueblo que, desde la ocupación de China por Gengis Khan en 1214, había iniciado una progresiva marcha de conquista hacia el Oeste. Este ambiente de vulnerabilidad ante la inminente llegada del pueblo mongol, provocó que dicha leyenda adquiriera gran intensidad a finales del medievo. Ante esta situación de alarma, el Papa Inocencio IV reunió en 1245 el Concilio de Lyon y decidió el envío de misioneros a Oriente. Sin duda, en muchos momentos las relaciones que se establecieron entre Oriente y Occidente gozaron de tolerancia mutua, fruto de la cual son las relaciones de viajes de misioneros como Jean du Plan de Carpin (que partiera hacia Oriente en 1245) o Guillaume de Rubrouck (que lo hiciera en 1253). No obstante, la Cristiandad no descansó completamente, y fueron varios los momentos en los que temió una nueva invasión tártara, por lo que la identificación de este pueblo con las fuerzas devastadoras del mal se perpetuó en el tiempo, recogiéndose este tema en la cartografía bajomedieval.

Además de las circunstancias históricas que abonaron el terreno para la germinación de esta leyenda, no hay que olvidar que la idea de que Alejandro Magno encerró a Gog y Magog nace dentro del seno de la cultura judía ${ }^{6}$, por lo que no resulta extraño que este tema aparezca den-

\footnotetext{
${ }^{2}$ Ezequiel, 38, 14-16; Apocalipsis, 20, 7-10; Apocalipsis, 19, 17-18.

${ }^{3}$ En relación con esta leyenda vid.: Budge, E. A. W., The life and exploits of Alexander the Great being a series of ethiopic texts edited from manuscripts in the British Museum and Bibliothèque nationale, Paris, Lonson, C. J. Clay and Sons, 1896, 2 vols; Graf, A., «La leggenda di Gog e Magog», en: VV.AA., Roma nella memoria e nelle immaginazioni del Medio Evo, Torino, Ermanno Loescher, 1883, vol. 2, pp. 507-563; Anderson, A. R., «The Arabic History of Dulcarnain and the Ethiopian History of Alexander», en Speculum, Cambridge, 6, (1931), pp. 434-445; Anderson, A. R., Alexander's gate, Gog and Magog, and the inclosed nations, Cambridge, Massachusetts, The Mediaeval Academy of America, 1932; Cary, G., The Medieval Alexander, Cambridge, Cambridge University Press, 1956; Ross, D. J. A., Alexander Historiatus. A Guide to Medieval Illustrated Alexander Literature, London, The Warburg Institute, University of London, 1963; Ross, D. J. A., «Alexander Historiatus, a Supplement», en Journal of the Warburg and Courtauld Institutes, London, XXX, (1967), pp. 383-388; Leake, J. A., The Geats of «Beowulf», Madison, Milwaukee and London, The University of Wisconsin Press, 1967; Boyle, J. A., «The Alexander Legend in Central Asia», en Folklore, 85, (1974), pp. 217-228; Delgado Pérez, Mª M., «El muro de Gog y Magog según el Ātär al-bilād de al-Qazwīn̄”, en Philologia Hispalensis, Sevilla, XIV, 2, (2000), pp. $183-192$.

${ }_{4}$ «Montañas del Caspio en las que Alejandro [Magno] vio árboles tan altos que sus copas tocaban las nubes. Aquí estuvo a punto de morir de no ser por Satanás que lo sacó de allí con su poder; y por sus trazas encerró aquí a los tártaros Gog y Magog y para ellos mandó hacer las dos imágenes de metal arriba dibujadas. También encerró aquí muy diversas gentes que no vacilan en comer todo tipo de carne cruda: de esta gente procederá el Anticristo y su fin será causado por el fuego que caerá del cielo y les confundirá». La traducción de este texto deriva de: VV. AA., Mapamundi del año 1375 de Cresques Abraham y Jafuda Cresques, Barcelona, Ebrisa, 1983, p. 81.

${ }^{5}$ Anderson, A. R., Op. cit., (1932), p. 14.

${ }^{6}$ Ibidem, pp. 16-20.
}

$A E A$, LXXVIII, 2005, 311, pp. 263 a 276 
tro de las cartas de la Escuela de Cartografía Mallorquina, realizadas mayoritariamente por judíos (convertidos forzosamente en 1391).

En el Atlas Catalán, los montes del Caspio, escenario en el que la leyenda se desarrolla, han sido desplazados al Extremo Oriente, territorio prácticamente desconocido donde había cabida para la imaginación. Con la extensión del conocimiento geográfico al que se había llegado en el momento de la realización del mapa no es de extrañar que estos montes, como escenario de dicha leyenda, tuvieran que ser desplazados de su geografía real hacia el océano del Norte ${ }^{7}$. Además, hay que señalar una posible influencia musulmana en la idea de trasladar esta frontera hacia el Noreste de Asia ${ }^{8}$, a diferencia de otros mapas anteriores, como son el mappamundi de Hereford (ca. 1280) ${ }^{9}$ y el de Ebstorf (siglo XIII) ${ }^{10}$ en los que esta leyenda se localiza en el Noreste de Europa ${ }^{11}$. De hecho, la cartografía islámica traslada el encierro de Yaŷûŷ wa Maŷūŷ (ياجوج وظجوج) al Noreste de Asia como se puede apreciar en algunos de sus mapas más representativos como son el mappamundi del Kitäb al-bad' wa-al-ta'rīkh $(977 / 1570)^{12}$ o el mappamundi de al-Idrīsī copiado en 1456 por 'Alī ibn Hasan al-Hūfĩ alQāsimi ${ }^{13}$.

La representación de los montes del Caspio en el Atlas Catalán responde formalmente a un dibujo bastante suelto, semejante al que presentan otros elementos orográficos en esta obra, y diferente a la fórmula recurrente en otros, a modo de cúmulo de piedras, como es el caso del Atlas africano, a excepción de un tramo en el que los montes del Caspio siguen este último diseño. La comparación de este motivo con otras cartas realizadas por Jafuda Cresques ${ }^{14}$, hijo de Cresques Abraham y heredero de su saber cartográfico, hacen pensar que la colaboración atribuida a Jafuda en el Atlas Catalán se llevara a cabo, al menos, en estos motivos. En el interior del espacio que encierran los montes del Caspio se representan árboles realizados de manera esquemática. Presentan un tronco muy esbelto y una copa redondeada muy frondosa, cubierta en algunos casos de flores y frutos. Algunos están quebrados, quizá por falta de espacio para la representación de los mismos. No obstante, en el Atlas Catalán se aprecia, en varios casos, falta de proporción entre diferentes elementos de una misma escena, por lo que este detalle podría interpretarse más bien como una alusión a los «árboles tan altos que sus copas tocaban las nubes» que viera Alejandro Magno, según narra la leyenda del Atlas Catalán, anteriormente mencionada.

De estos dos espacios tras los montes del Caspio, el localizado en la zona más septentrional, está reservado a la representación del «gran senyor princep de Gog y Magog» (Fig. 1). Aparece como un soberano a caballo y bajo un quitasol, símbolo de distinción social. Como signos de soberanía exhibe además una corona flordelisada de la que sobresale una estructura

\footnotetext{
${ }^{7}$ Ibidem, p. 87.

${ }^{8}$ Sin duda existe cierta relación entre la cartografía islámica y cristiana bajomedieval en la localización de dicho encierro en el Noroeste asiático. Posiblemente este hecho se deba a la influencia que ejercen los geógrafos musulmanes en lo que a la leyenda del Encierro se refiere, como ya señaló A. R. Anderson, por lo que se trataría de una influencia en el concepto geográfico. Por lo que respecta a la influencia desde el punto de vista cartográfico de los mapas islámicos en las cartas náuticas europeas vid.: Maqbul Ahmad, S., «Cartography of al-Sharīf al-Idrīsī», en: Harley, J. B., y Woodward, D., Cartography in the Traditional Islamic and South Asian Societies, The History of Cartography, Chicago \& London, The University of Chicago Press, 1992, vol. 2, pp. 156-174, esp. p. 172, y las referencias bibliográficas que aporta respecto a este tema.

${ }^{9}$ Hereford Cathedral, Hereford (Reino Unido).

${ }^{10}$ Kloster Ebstorf, Ebstorf (Alemania). Este mapa, conservado los últimos años de su vida en los Archivos del Estado de Hannover (Alemania), fue destruido en 1943 a consecuencia de un bombardeo, y de él tan sólo se conservan reconstrucciones realizadas a partir de reproducciones anteriores.

${ }^{11}$ Anderson, A. R., Op. cit., (1932), pp. 25, 29 y capítulo V: «Alexander's (Dulcanian's) Gate and Rampart (Wall of Gog and Magog) shifted to Eastern or Northeastern Asia», pp. 91-104.

${ }^{12}$ Bodleian Library, Oxford (Reino Unido), Ms. Laud. Or. 317, ff. 10v-11.

${ }^{13}$ Bodleian Library, Oxford (Reino Unido), Ms. Pococke 375, ff. 3v-4.

${ }^{14}$ Carta datada en el siglo xIv y atribuida a Jafuda Cresques, Bibliothèque nationale de France, Paris (Francia), Rés. Ge AA 751 .
}

AEA, LXXVIII, 2005, 311, pp. 263 a 276 

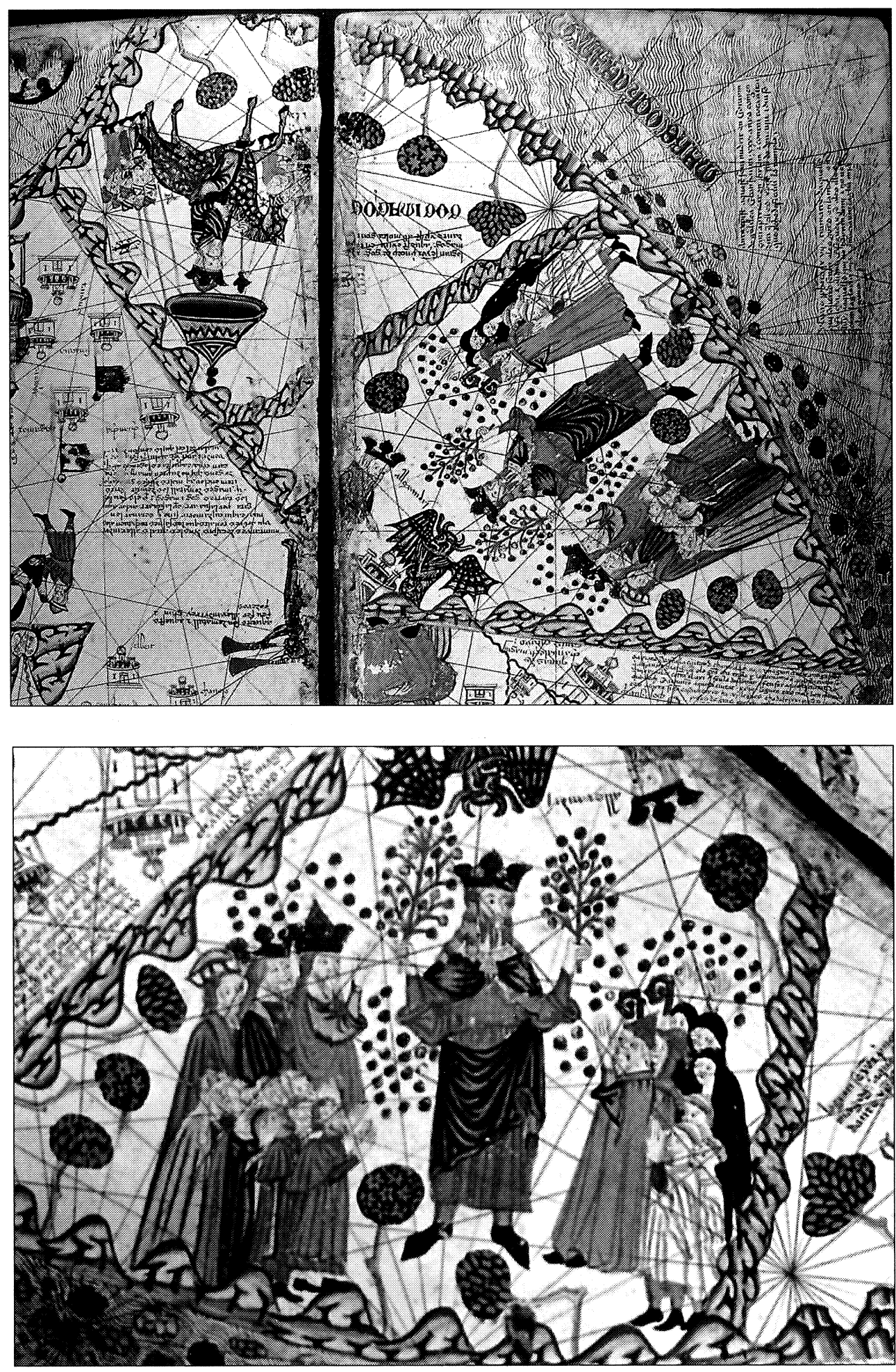

Fig. 1. Gog y Magog y el Anticristo. Atlas Catalán, B.n.F., Paris (Francia), Ms. Espagnol 30. Reproducido de VV. AA., Mapamundi del año 1375 de Cresques Abraham y Jafuda Cresques, Barcelona, Ebrisa, 1983. La fotografía del mapa está orientada al Norte.

Fig. 2. El Anticristo. Atlas Catalán, B.n.F., Paris (Francia), Ms. Espagnol 30. Reproducido de VV. AA., Mapamundi del año 1375 de Cresques Abraham y Jafuda Cresques, Barcelona, Ebrisa, 1983. 
semiesférica que recuerda al tipo de corona imperial, y un cetro rematado también con la flor de lis. Luce barba y una larga melena rizada. Viste túnica azul con faja de tiraz y cruzada en el pecho. Alrededor de él se concentran todos su vasallos, los cuales portan lanzas, lanzas que exhiben estandartes con el escorpión, efigie del diablo. Aparecen organizados en dos grupos muy apretados que caminan delante y detrás del caballo de su señor. Los que van detrás de éste se agarran de la cola del animal para protegerse de las tormentas de arena, al igual que lo hacen otros personajes que conducen animales en el Atlas Catalán. Visten saya corta o gonela, como se denominó a esta prenda respectivamente en Castilla y en Aragón. Presenta un corte muy sencillo, ciñéndose a la cintura con un cinturón, y se mezclan diferentes colores, de manera que estos personajes, superpuestos unos sobre otros, no se confundan entre sí. La falda corta permite ver las calzas enrolladas y atadas bajo la rodilla, tal como las llevaban la gente humilde en la Edad Media ${ }^{15}$. Calzan lo que posiblemente sean zapatas ${ }^{16}$ y están tocados con sombreros o capell de sol, como son llamados en Castilla y Aragón respectivamente, de copa redonda, aunque la abertura en la vuelta del mismo es semejante a la de los capiellos redondos ${ }^{17}$. Estos son también de diferentes colores. Esta representación está acompañada de la siguiente leyenda: «Lo gran senyor princep de Gog e de Magog. Aquest exirà en temps $\mathrm{d}^{\prime}$ Antechrist ab molta gent» ${ }^{18}$.

En el espacio meridional de los montes del Caspio aparece la imagen entorno a la cual se centra este artículo (Fig. 2). Se trata de una figura coronada que porta en sus manos unas ramas de las que caen frutos dorados, y a cuyos pies se postran indistintamente personajes de diferentes estamentos sociales, laicos y seglares. Hasta el momento, la identificación de esta figura ha variado entre la representación del Anticristo ${ }^{19}$ y la imagen de Dios en el Paraíso Terrenal, donde los Bienaventurados disfrutan de los frutos paradisíacos o bien son recompensados con la palma de la inmortalidad ${ }^{20}$.

Desde el punto de vista de la tradición iconográfica de la imagen del Paraíso, hay que señalar en primer lugar que esta escena no presenta ninguno de los elementos característicos del mismo como puedan ser los cuatro ríos paradisíacos ${ }^{21}$. Por otro lado, resulta extraño que la supuesta representación de Dios carezca de nimbo. Además, la leyenda que acompaña esta escena, y que será mencionada posteriormente, alude a esta figura como «Antichristo»,

${ }^{15}$ Menéndez Pidal, G., La España en el siglo xiIr leída en imágenes, Madrid, Real Academia de la Historia, 1986, p. 61.

16 Ibidem, p. 100.

${ }^{17}$ Ibidem, pp. 84 y 86 .

18 «El gran señor príncipe de Gog y Magog. Éste aparecerá en tiempos del Anticristo con mucha gente». La traducción de este texto deriva de VV. AA., Op. cit., p. 87.

${ }^{19}$ Llompart i Moragues, G., «Aspectes iconogràfics», en: VV. AA., L'atlas catala de Cresques Abraham, primera edició en el sis-cents aniversari de la seva realització, Barcelona, Diafora, 1975, p. 51 y Llompart i Moragues, G., Les il.lustracions religioses de l'atlas mallorquí del jueu Cresques Abraham, Palma de Mallorca, Reial Academia de Bellas Arts de Sant Sebastià, 1989, p. 9; VV. AA., Op. Cit., (1983), p. 87. No obstante, G. Llompart i Moragues interpreta esta imagen como una «puntada anticristiana», idea que yo no comparto, como posteriormente explicaré.

${ }^{20}$ Buchon, J. A. C., y Tastu, J., Notice sur un atlas en langue catalane, de l'an 1374: conservé parmi les manuscrits de la Bibliothèque du Roi, Paris, 1841, p. 141. Esta obra fue recogida en un artículo: Buchon, J. A. C., y Tastu, J., «Notice d'un Atlas en langue catalane, manuscrit de l'an 1375, conservé parmi les manuscrits de la Bibliothèque Royale sous le No. 6816, fonds ancien, in-folio maximo", en Notices et extraits des manuscrits de la Bibliothèque du Roi et autres bibliothèques, 14 (1843), pp. 1-152; Lelewel, J., Geographie du Moyen Age, Bruxelles, 1852, t. 2, p. 62; Freisleben, H. C., Der Katalanische Weltatlas vom Jahre 1375 nach dem in der Bibliothèque Nationale, Paris, verwahrten Original farbig wiedergegebe: Mit einer Einführung und übersetzungen von Hans-Christian Freiesleben, Stuttgart, Antiquarium, 1977, p. 24; Bibliothèque Nationale de France, «L'Atlas Catalan». URL: http://expositions.bnf.fr/ciel/catalan/; Gow, A., «Gog and Magog on Mappaemundi and Early Printed World Maps: Orientalizing Ethnography in the Apocalyptic Tradition», en Journal of Early Modern History, Leiden, 2, (1998), 1, pp. 76-77; Bibliothèque Nationale de France, Opus Species, Mapa mondí, l'Atlas Catalan, une carte du monde au XIv siècle (Recurso electrónico), Paris, Montparnasse Multimedia, 1998.

${ }^{21}$ Alessandro Scafi, al que tuve el placer de conocer en el Warburg Institute de Londres en agosto de 2003, sin duda el mayor investigador de la representación del Paraíso en la cartografía medieval, afirmó no tratarse de una imagen paradisíaca tan sólo con mi mera descripción de la escena. 
al igual que ocurre en el caso del texto de Gog y Magog anteriormente mencionado. Por último, he de destacar que, tras rastrear la iconografía del Anticristo, he podido identificar esta escena con uno de los momentos de su vida en el que se presenta como falso profeta realizando milagros.

Dentro de la exégesis medieval, el Anticristo fue concebido, entre otros aspectos, como el falso profeta que engañaba fingiendo ser Cristo ${ }^{22}$. Dicha concepción se remonta a los textos bíblicos, y así, en el evangelio de San Mateo se afirma en boca de Jesucristo: «Cuidad que nadie os engañe. Porque vendrán muchos usando mi nombre y diciendo: «Yo soy el Cristo» (...) Surgirán muchos falsos profetas y engañarán a muchos» ${ }^{23}$. Progresivamente, a medida que en la Edad Media se reconocieron similitudes entre la vida de Cristo y la del Anticristo, se fueron añadiendo algunos detalles a la leyenda de este último, que originalmente no se encontraban en las fuentes apocalípticas. De este modo, se forjó la imagen del Anticristo como el antitipo de Cristo. La obra de Abbot Adso de Montier-en-Der (ca. 910-992) titulada Libellus de Anticristo (ca. 954) ${ }^{24}$, favoreció la configuración de una coherente vida del Anticristo alcanzando una gran repercusión hasta finales del medievo, tanto en lo que a discusiones teológicas se refiere, como en la creación de la imagen artística y literaria de éste. La influencia de dicho autor se aprecia en dos trabajos enciclopédicos realizados en la Baja Edad Media y que alcanzarían una gran trascendencia en este momento: el Compendium theologicae veritatis (ca. 1265) de Hugh Ripelin de Strassburg (m. 1268) y el Tractatus de victoria Christi contra Antichristum (1319) de Hugh de Newcastle (1280-1322) ${ }^{25}$. A través de estos trabajos, la vida del Anticristo quedaba perfectamente perfilada con la inclusión de detalles exegéticos relativos a su nacimiento, milagros, persecución y muerte, así como de las leyendas de Gog y Magog, y Enoc y Elías. El Anticristo, como falso profeta, comenzará a declarar ser el Mesías, promulgará nuevas leyes para destruir la ley de Dios y proclamará que Cristo ha sido un falso Dios. En dichas predicaciones el Anticristo llevará a cabo milagros para convencer a las gentes. Dentro de los milagros ejecutados por el Anticristo se incluye el prodigio de hacer florecer y dar frutos las raíces de un árbol dispuesto de manera invertida o bien unas ramas secas, prodigio que aparece recogido en el Atlas Catalán.

Antes de pasar al estudio de esta escena, es conveniente tratar de analizar esta representación en otras obras bajomedievales para facilitar la interpretación de la ilustración iconográfica de Cresques Abraham. A finales del siglo XII, hace su aparición el primer ejemplo de un nuevo género, un ciclo narrativo en el que se ilustra la vida y muerte del Anticristo. El Hortus deliciarum de Herrad de Hohenberg, datado entre 1170 y 1190, contiene dicho ciclo ${ }^{26}$. En el folio $241 \mathrm{v}$, formando parte de la historia de este personaje, aparece el milagro de hacer florecer las ramas secas de un árbol ante la sorpresa y admiración de sus seguidores, judíos en este caso (Fig. 3).

Por otro lado, dentro de las obras en las que también aparece dicha imagen se podría destacar el corpus de Apocalipsis Anglo-Normandos, un grupo de manuscritos ilustrados que tuvieron especial popularidad y ejercieron una considerable influencia a finales de la Edad Me-

\footnotetext{
${ }^{22}$ En relación con la figura del Anticristo en la Edad Media vid.: McGinn, B., «Portraying Antichrist in the Middle Ages», en: VV.AA., The use and abuse of eschatology in the Middle Ages, Leuven (Belgium), Leuven University Press, 1988, pp. 1-48; Emmerson, R. K., Antichrist in the Middle Ages. A Study of Medieval Apocalypticism, Art, and Literature, Manchester, Manchester University Press, 1981.

${ }^{23}$ San Mateo, 24, 4-5, y 11.

${ }^{24}$ Vid.: ADSO, Libellus de Antichristo, ed. Ernst Sackur, Sibyllinische Texte und Forschungen, Halle, Max Niemeyer, 1898, pp. 99-113; Traducido por: Wright, J., The Play of Antichrist, Toronto, Pontifical Institute of Medieval Studies, 1967, pp. $100-110$.

${ }^{25}$ Vid.: Borgnet, S. A., Albertus Magnus, Opera omnia, 34, Paris, 1896.

${ }^{26}$ Vid.: Green, R. et al., Herrad de Hohenbourg. Hortus Deliciarum, Leiden-London, Warburg Institute, 1979.
} 

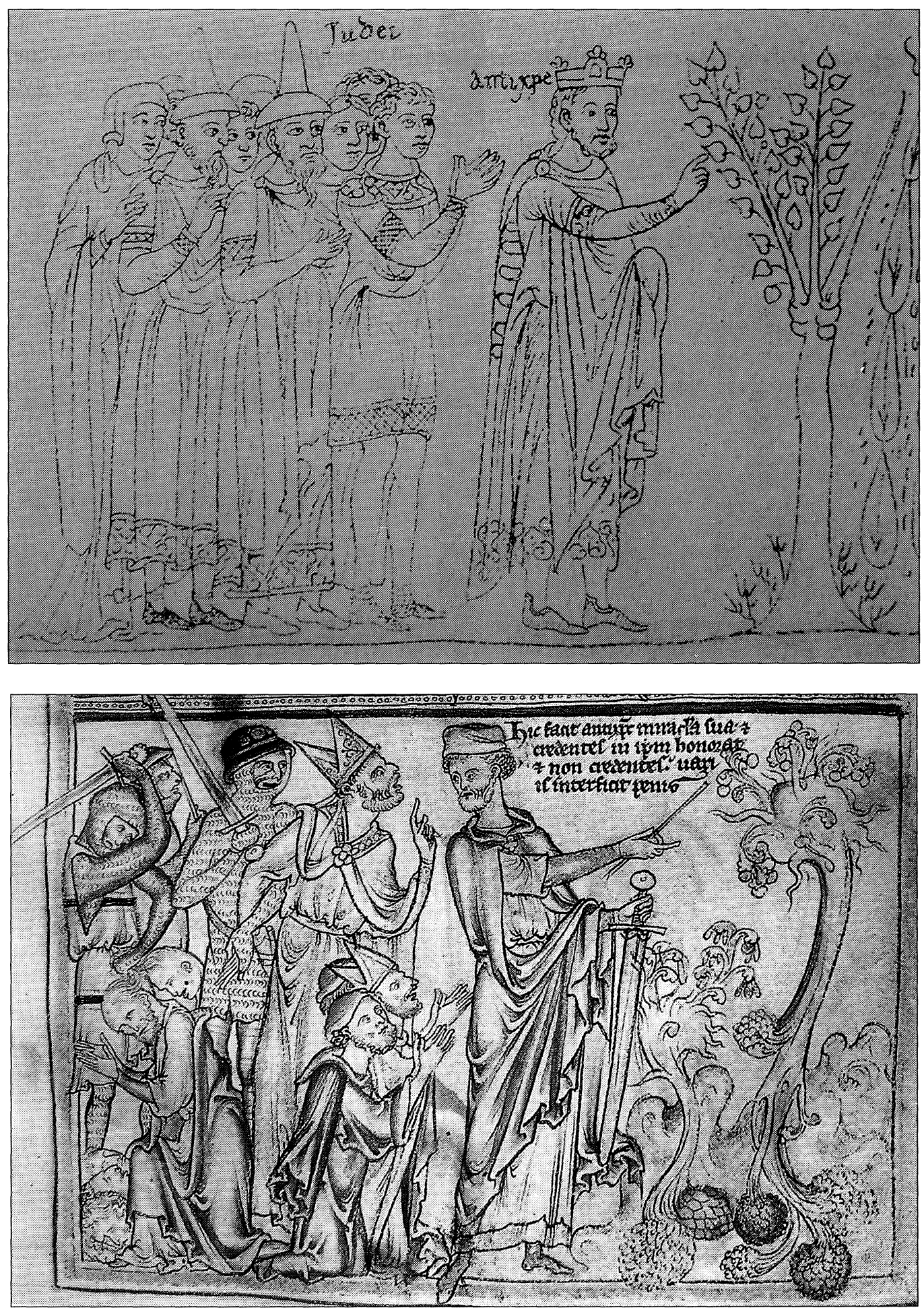

Fig. 3. El Anticristo realizando un milagro. Hortus deliciarum, f. 241v de Herrad de Hohenberg. Reproducido de VV.AA., The Lambeth Apocalypse. Manuscript 209 in Lambeth Palace Library, London, Harvey Miller Publishers, 1990, fig. 29.

Fig. 4. El Anticristo realizando un milagro. Apocalipsis de the Pierpont Morgan Library, New York (EE.UU.), Ms. 524, f. 7. Reproducido de R. K. Emmerson, Antichrist in the Middle Ages, Manchester, Manchester University Press, 1981 , figure 4. 
dia (ca. 1250-1450) ${ }^{27}$. En el Apocalipsis de la Pierpont Morgan Library ${ }^{28}$ aparece la representación del Anticristo realizando el milagro de hacer florecer las raíces de unos árboles dispuestos de manera invertida. A sus pies, se postran sus fieles convertidos ante el milagro. Las vestimentas y atributos que estos exhiben permiten reconocer entre los seguidores del Anticristo personajes de diferentes estamentos sociales, dentro de los cuales redundan los religiosos tocados por mitra (Fig. 4). Esta misma escena está representada de manera muy semejante en el Apocalipsis Lambeth ${ }^{29}$ (Fig. 5). Quizá, el Apocalipsis de París ${ }^{30}$ también contaba en origen con esta representación realizada en el folio actualmente perdido, tras el f. $17 \mathrm{v}^{31}$.

Por último, en lo que respecta a la representación de los milagros del Anticristo hay que destacar el gran desarrollo que experimenta esta escena en los Block Book Apocalipsis ${ }^{32}$, aunque cronológicamente son posteriores a la aparición de esta imagen en los mapas medievales, por lo que en parte exceden del tema aquí tratado.

En la escena del Atlas Catalán, el Anticristo, sostiene en sus manos unas ramas secas de las que milagrosamente ha hecho brotar frutos dorados con los que seduce a sus fieles que le veneran maravillados. El Anticristo es el personaje de mayores dimensiones, lo que debe entenderse como una distinción jerárquica. Aparece tocado con la corona flordelisada. Presenta barba y una larga melena ondulada que le cae sobre los hombros. Viste saya naranja sobre la que se dispone un traje largo de mangas anchas del mismo color, que pudiera identificarse con una piel, aljuba o almejía ${ }^{33}$. Sobre ésta se dispone un manto azul unido con un broche en el centro. Adorando al Anticristo se representan personajes de diferentes estamentos de la sociedad, seglares a su derecha y religiosos a su izquierda. Hay que señalar, que además de actitudes de veneración juntando las manos, algunos de estos personajes, en concreto las dos monjas, están representados con las manos en alto como si intentaran atrapar esos frutos dorados. No en vano, se llegó a afirmar que el Anticristo emplearía como artimaña el intentar persuadir a las gentes con regalos.

En lo que respecta al grupo de laicos hay que destacar que están divididos en dos jerarquías a través de diferentes tamaños. Posiblemente también se hace distinción jerárquica por la mayor o menor cercanía al Anticristo, representándose las mujeres en un segundo plano. De mayor tamaño están figurados dos reyes coronados y otro personaje masculino con un tocado. En lo que respecta a la corona hay que destacar que ésta es flordelisada, aunque la del rey más próximo al Anticristo recuerda al tipo de corona imperial por la estructura interna a modo de capirote puntiagudo de color rojo decorado con pequeñas esferas. Estos tres personajes visten capa o manto como traje de encima, dispuesto bien sobre los dos hombros, como aparece en los personajes de la izquierda, o bien cruzando las puntas sobre el hombro izquierdo y dejando el brazo derecho al descubierto ${ }^{34}$. Bajo éste, según se puede apreciar en el personaje más próxi-

\footnotetext{
${ }^{27}$ En relación con este corpus de obras vid.: Delisle, L., y Meyer, P., L'Apocalypse en français au xiIle siècle, Société des anciens textes français, facsímil, París, 1900, texto, París, 1901; Henderson, G., «Studies in English Manuscript Illumination», en Journal of the Warburg and Courtauld Institutes, London, XXX, (1967), pp. 71-137, y XXXI, (1968), pp. 103-147, esp. Part II, (1967), pp. 104-137 y Part III, (1968), pp. 103-147; Poesch, J. J., , Antichrist imaginery in Anglo-French Apocalypse Manuscripts, Ann Arbor (Michigan), UMi, Disertation Services, [2003]; Lewis, S., Reading images. Narrative discourse and reception in the thirteenth-century illuminated apocalypse, Cambridge, Cambridge University Press, 1995.

${ }^{28}$ Pierpont Morgan Library, New York (EE.UU.), Ms. 524, f. 7.

${ }^{29}$ Lambeth Palace Library, London (Reino Unido), Ms. 209, f. 12.

${ }^{30}$ Bibliothèque nationale de France, Paris (Francia), Ms. Fr. 403.

${ }^{31}$ Henderson, G., «Studies in English Manuscript Illumination», en Journal of the Warburg and Courtauld Institutes, London, XXX, (1967), p. 110.

${ }^{32}$ Para la representación del milagro del Anticristo haciendo florecer las ramas de un árbol vid.: el Block Book de Nuremberg, f. 5v, del que existen ediciones facsimilares: Musper, H. T., ed., Der Antichrist und die fünfzehn Zeichen, Munich, Prestel, 1970. La imagen está recogida en: McGinn, B., Op. cit., ilustración 13, p. 41.

${ }^{33}$ Menéndez Pidal, G., Op. cit., p. 65.

34 Ibidem, pp. 72-73.
}

AEA, LXXVIII, 2005, 311, pp. 263 a 276 
mo al Anticristo, llevan saya y pellote. De entre los personajes representados en un nivel inferior, y de menor tamaño, se puede reconocer a cuatro personajes femeninos y dos masculinos. En lo que respecta a los primeros hay que señalar que todos aparecen con tocas. El segundo personaje femenino de la izquierda, que exhibe más la indumentaria, viste saya gris sobre la que se dispone un atuendo muy largo, posiblemente un brial, de color azul oscuro. Dicha vestimenta es muy significativa de lo que fue la moda en el siglo XIV ya que por un lado presenta mangas con una prolongación colgante a la altura de los codos, rasgo característico de la moda internacional del XIV, que progresivamente se va exagerando, y por otro, un amplio escote redondo que dejaba desnuda la garganta y parte de los hombros, introducido en la moda femenina hacia mediados de esta centuria ${ }^{35}$. Los dos personajes femeninos de la izquierda que no quedan ocultos tras el grupo, presentan capa o manto. Por lo que respecta a los masculinos, hay que señalar que visten garnachas sobre la saya. Las garnachas fueron prendas de vestir de encima muy empleadas por distinto tipo de gente. Permitían sacar los brazos por las escotaduras laterales u ocultarlos ${ }^{36}$. El personaje de la izquierda luce una capucha bajada.

Del grupo de religiosos se pueden distinguir un personaje tocado posiblemente con mitra de obispo, otro con capelo cardenalicio, tres monjas y tres monjes. También se puede hacer una distinción jerárquica entre personajes de mayor y menor tamaño, siendo los más pequeños los monjes, y entre la mayor o menor cercanía al Anticristo, estando representadas las monjas en un último plano y el obispo en primera línea. Entre los elementos distintivos de los religiosos hay que destacar que en el fondo asoman dos báculos dorados. Todos los personajes de esta escena que enseñan sus pies están calzados con zapatas y llevan calzas ${ }^{37}$. Los colores de las vestimentas de estos grupos alternan de manera que no se crea confusión alguna y se puede diferenciar sin problema a los distintos personajes.

La representación del Anticristo del Atlas Catalán está acompañada de la siguiente leyenda: «Antechrist. Aquest serà nudrit en Goraym de Galilea e con haurà $\cdot X X X \cdot$ anys començarà a preicar en Jherusalem e contra tota veritat dirà que ell és Christ fill de Déu viu. e diu-se que rehedifficarà lo Temple» ${ }^{38}$. Como ya se ha mencionado anteriormente, al margen del análisis iconográfico, esta leyenda reconocía al personaje de esta escena como la representación del Anticristo. En la información facilitada en dicho texto se alude a algunos pasajes de la vida de este personaje, en concreto a su nacimiento, predicaciones y al pasaje de la reedificación del templo. El lugar del nacimiento del Anticristo varía según las fuentes consultadas. En el Libro de las maravillas del mundo de Jean de Mandeville, en la descripción de Galilea, se menciona Corasaín como el lugar de nacimiento del Anticristo: «Esta Galilea es una provincia de la tierra de Promisión, y en estas provincias son las ciudades de Nay, Cafarnaún y Betsaida y Corosaín. (...) En Corosaín ha de nacer el Anticristo» ${ }^{39}$. La presencia del Anticristo en esta obra pone de relieve el alcance de las cuestiones relacionadas con éste que exceden del ámbito exegético e influencian incluso la literatura popular. Del mismo modo que Mandeville, el PseudoMethodius y Adso coincidían en mencionar Corasaín como el lugar del nacimiento del Anticristo.

Como ya se ha mencionado, para la representación del continente asiático Cresques Abraham recurre a los testimonios de aquellos viajeros, como Marco Polo, o «falsos» viajeros, como Jean de Mandeville, cuyas noticias fundaron el conocimiento que durante mucho tiempo tuvo

\footnotetext{
${ }^{35}$ Bernis Madrazo, C., Indumentaria medieval española, Madrid, C. S. I. C., 1955, pp. 32-33.

${ }^{36}$ Menéndez Pidal, G., Op. cit., pp. 65-66 y 59.

${ }^{37}$ Ibidem, pp. 61 y 100.

38 «Anticristo. Éste será criado en Goraym de Galilea, y cuando tenga treinta años empezará a predicar en Jerusalén; contrariamente a la verdad, proclamará que él es Cristo, hijo de Dios vivo, y se dice que reedificará el Templo». La traducción de este texto deriva de VV.AA., Op. cit., (1983), p. 87.

${ }^{39}$ Mandeville, Jean de, Libro de las Maravillas del Mundo, Libro I, capítulo XXX, Madrid, Visor, 1984 p. 74.
} 
Europa de este continente. La popularidad que adquirieron estas obras tuvo como consecuencia su difusión por toda Europa, y la Corona de Aragón no fue una excepción en lo que a esto se refiere. Ya se ha puesto de relieve la conexión entre el Atlas Catalán, y por extensión todas las cartas que le siguen en este aspecto, con la obra de Mandeville. Posteriormente, se retomará de nuevo esta comparación. Hasta entonces, baste resaltar que de hecho hay constancia de la adquisición de estas obras por el infante don Juan, el futuro Juan I, el mismo que supuestamente enviara el Atlas Catalán a Carlos VI, rey de Francia, en conmemoración de su coronamiento. En una carta fechada en Vich, el 13 de agosto de 1380: «Rey molt excellent e avoncle molt car: ... nos nos dedelitam molt en legir e axi propiament en frances com en nostra lengua matexa, perque us pregam que ns vullats enviar tres libres escrits en lenguatge frances, ço es les canoniques de França, Titus Livius e Mendivila...» ${ }^{40}$. Éste mismo insistía días más tarde a su madre política, la duquesa de Bar: «Molt cara mare nostra e molt amada: ... noresmenys vos pregam, cara mare, que ns trametats com enans porets lo libre de Johan de Mendrevile e le romanç de Mexaut .... ${ }^{41}$. El manuscrito de Mandeville conservado en la Biblioteca de El Escorial ${ }^{42}$, escrito en lengua aragonesa, es quizá el mismo que el rey de Francia o la duquesa de Bar, remitirían al príncipe don Juan ${ }^{43}$. La biblioteca del infante don Juan quizá facilitaría el contacto de Cresques Abraham con estas obras ya que no hay que olvidar que la monarquía aragonesa no sólo fue cliente predilecto de Cresques Abraham, sino también protectora del judío mallorquín.

En relación con la continuidad de la representación de esta leyenda dentro de la cartografía mallorquina, hay que destacar en primer lugar que de las cartas que se han conservado hasta la actualidad, son realmente excepcionales aquellas que geográficamente se extendían más allá de Oriente Próximo. Tan sólo se conocen el Mappamundi Catalán Estense (ca. 1450) y el de Estambul (ca. 1380). Por lo que respecta a la carta de Dulcert (1339) ${ }^{44}$, G. de Reparaz afirmó que posiblemente esta carta incluyera una tercera piel de pergamino en la zona oriental ya que algunas figuras y textos están amputados ${ }^{45}$. Sin duda, es cierto que algunas representaciones y leyendas están cortados, sin embargo, no creo que falte un tercer folio, sino tan sólo unos centímetros, ya que las dos redes de rumbos de los dos pergaminos están centradas y no hay rastro del desarrollo de una tercera que debiera corresponderse con la tercera piel de pergamino. Por otro lado, de las figuras que aparecen parcialmente amputadas, hay que destacar la representación del punto cardinal Este a través de la imagen del sol. El hecho de que aparezca dicha representación es indicativo del límite de la representación de la carta por este extremo.

Para el cotejo de la escena representada en el Atlas Catalán con las obras mallorquinas anteriormente mencionadas, en primer lugar se hará referencia a la carta Estense, que aunque es cronológicamente anterior a la de Estambul, presenta la representación del continente asiático de manera completa y además, las representaciones que en ésta aparecen, contribuyen a reconocer en la carta de Estambul una obra mallorquina, aunque dicho estudio no se llevará a cabo en este artículo ya que excede de la finalidad del mismo.

El Mappamundi Catalán Estense (ca. 1450) ${ }^{46}$, siguiendo la representación del Atlas Catalán, presenta en la zona Nororiental de Asia la imagen de los montes del Caspio a modo de

\footnotetext{
${ }^{40}$ Rubio i Lluch, A., Documents por l'historia de la cultura catalana mig-eval, Barcelona, 1908-1921, vol. II, p. 221.

${ }^{41}$ Ibidem, p. 225.

${ }^{42}$ Biblioteca del Real Monasterio de San Lorenzo de El Escorial, Madrid, M-iii-7.

${ }^{43}$ Vid.: Liria Montañés, P., 'Libro de la maravillas del mundo' de Juan de Mandevilla, Zaragoza, Caja de Ahorros de Zaragoza, Aragón y Rioja, 1979.

${ }^{44}$ Bibliothèque nationale de France, Paris (Francia), Rés. Ge B. 696.

${ }^{45}$ Reparaz, G. de, Catalunya a les mars, navegants, mercaders $i$ cartògrafs catalans de l'Edat Mitjana $i$ del Renaixement, Barcelona, Mentora, 1930, p. 81.

${ }^{46}$ Biblioteca Estense Universitaria, Modena (Italia), C. G. A. 1.
}

$A E A$, LXXVIII, 2005, 311, pp. 263 a 276 

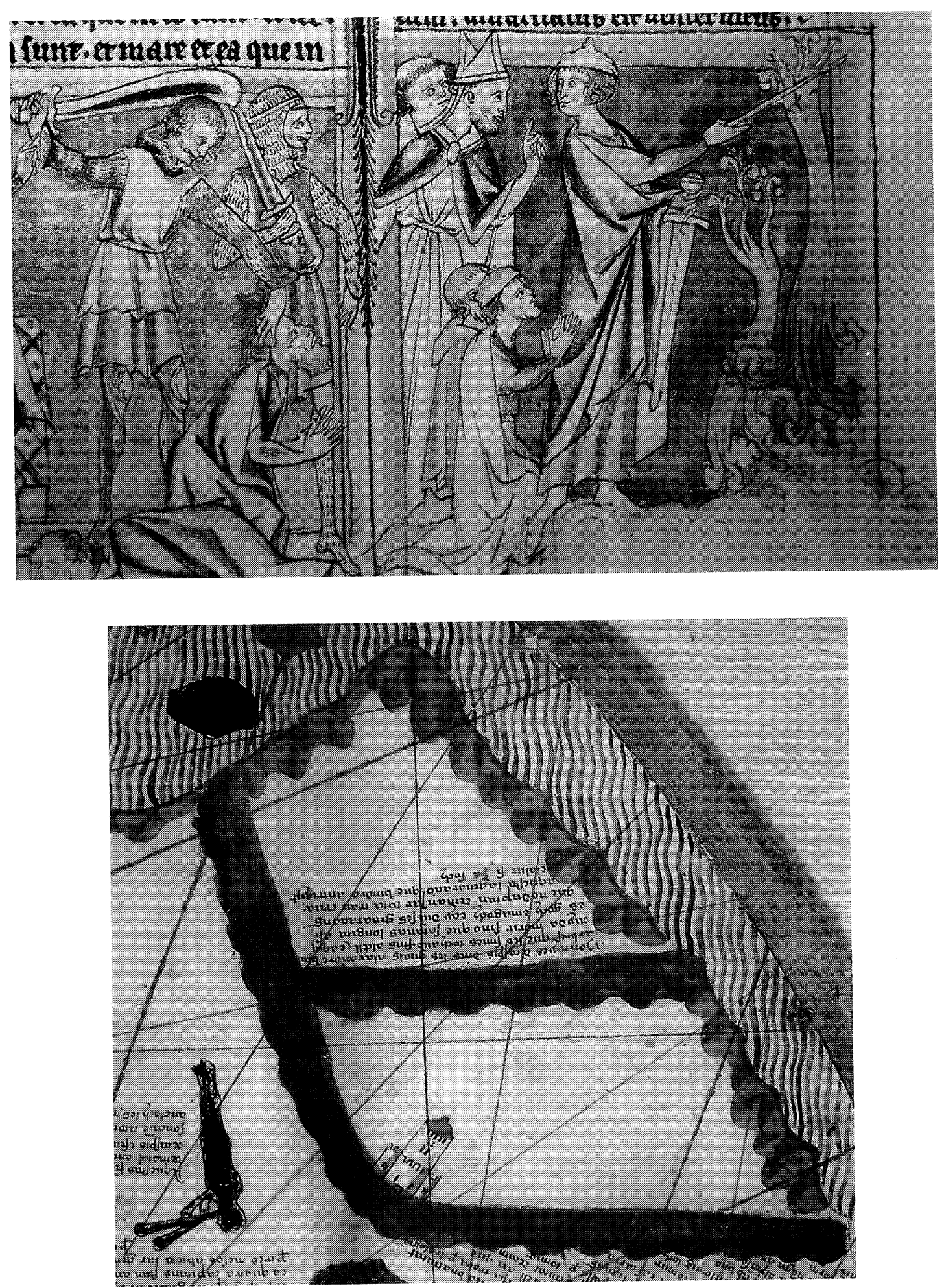

Fig. 5. El Anticristo realizando un milagro. Apocalipsis de the Lambeth Palace Library, Londres (Reino Unido), Ms. 209, f. 12. Reproducido de VV.AA., The Lambeth Apocalypse. Manuscript 209 in Lambeth Palace Library, London, Harvey Miller Publishers, 1990.

Fig. 6. Montes del Caspio. Mappamundi Catalán Estense, Biblioteca Estense Universitaria, Modena (Italia), C. G. A. 1. Reproducido del Facsímil del Museo Naval (Madrid), R. C. La fotografía del mapa está orientada al Norte. 
cordillera continua y cerrada sobre si misma, que cercan un espacio, a su vez dividido por otro tramo montañoso (Fig. 6). La similitud de esta imagen con la que apareciera en el Atlas Catalán se afianza en la representación de nuevo de una ciudad en el extremo Suroeste, así como de los dos trompeteros que también aparecen en el mapa de Cresques Abraham. Sin embargo, curiosamente, los espacios cercados que aparecen tras estos montes carecen de representación alguna ${ }^{47}$. No obstante, el recuerdo de esta leyenda se manifiesta no sólo a través de la representación de los montes del Caspio, sino gracias a un texto, muy similar al del Atlas Catalán en el que se afirma: «Montaynes de Caspis dins les quals Alexandre viu arbres que les simes tochauen fins al cell, e aquí cuida morir, sino que Satanas l'on gita; asi es Goch e Magoch e a.y diuerses genaracions que no duptan de manjar tota carn crua; aquesta la generacio que vindra Antichrist la lur fi sera foch» ${ }^{48}$.

El fragmento de carta mallorquina conservado en Estambul (ca. 1380) ${ }^{49}$ recoge la representación del Norte del continente asiático, incluyendo las mismas escenas que aparecen en el Atlas Catalán y en el Mappamundi Catalán Estense (Fig. 7). Desgraciadamente de esta carta no queda nada más que un fragmento, y en éste no se incluye la representación de Gog y Magog y el Anticristo tras los montes del Caspio. De lo que correspondería a esta escena, tan sólo se conserva lo que sería la delimitación física de dicho encierro en la zona Norte, a través de la cordillera que separa este espacio del Mar-Océano, y una copa de árbol amputada, que supuestamente se correspondería con los que viera Alejandro, según rezan las leyendas del Atlas Catalán y el Mappamundi Catalán Estense. Los elementos pertenecientes a esta escena son un claro indicio de que en esta carta también se representó esta leyenda, y dada la gran similitud que guardan las ilustraciones que aparecen en dicho fragmento, con las que aparecen en los mapas anteriores, especialmente con el Atlas Catalán, me aventuraría a afirmar que dicha escena sería muy semejante a la que ilustrara Cresques Abraham.

En cuanto a la Carta de Juan de la Cosa $(1500)^{50}$ (Fig. 8), aunque se inserta en los arranques de la Edad Moderna, dentro de la Escuela de Cartografía Sevillana, presenta muchos elementos que la vinculan con la cartografía medieval, en concreto con la Escuela Mallorquina ${ }^{51}$. Dentro de aquellos aspectos que relacionan esta carta con la cartografía mallorquina se encuentra la representación de los montes del Caspio en el extremo Noreste del mapa. Del mismo modo que en las cartas mallorquinas anteriormente mencionadas, estos montes dibujan un se-

\footnotetext{
${ }^{47}$ G. Llompart i Moragues ha mencionado en muchas ocasiones el carácter anticristiano de las cartas mallorquinas realizadas por artífices judíos o forzosamente conversos, plasmado según él, con bastante claridad, en el Atlas Catalán. La representación de la figura del Anticristo es considerada una «puntada anticristiana» por este autor. Además, insiste en que los artistas judeoconversos que le siguieron, quizá para ahorrarse problemas, optaron por el camino más práctico de guardar silencio, y omitieron esta leyenda y esta representación, en Llompart i Moragues, G., La pintura medieval mallorquina, su entorno cultural y su iconografía, Palma de Mallorca, Caja de Ahorros y Monte de Piedad de las Baleares, 1977, v. 1, p. 177. Aunque en el Mappamundi Catalán Estense de Módena es cierto que se omite la representación, tras el análisis de la imagen del Anticristo creo que debe olvidarse el espíritu «anticristiano» de esta obra y asumir, al menos la representación del Anticristo, como perfectamente acorde con la ortodoxia iconográfica cristiana. Además, este autor, incidiendo en el carácter anticristiano de estas obras, menciona que no existe ninguna alusión a la figura de Cristo en el Atlas Catalán, en: Ibidem, lo que no es cierto, ya que en la leyenda que acompaña a la representación de los Reyes Magos se hace mención expresa a Jesucristo.

48 «Montes de Caspio, donde Alejandro vió árboles que alcanzaban el cielo y aquí creyó morir, de no ser por Satanás que le sacó de allí; aquí se encuentran Gog y Magog, y varios pueblos que no vacilan en comer carne cruda; de este pueblo vendrá el Anticristo y su fin será por el fuego». La traducción de este texto deriva de Milano, E. y Batini, A., Mapamundi Catalán Estense, Barcelona, Moleiro, 1996, p. 157.

${ }^{49}$ Topkapi Saray Kutuphane, Estambul (Turquía), H. 1828.

${ }^{50}$ Museo Naval, Madrid, en exposición permanente.

${ }^{51}$ Aunque ya se ha mencionado en numerosas ocasiones la influencia de la Cartografía Mallorquina en la Carta de Juan de la Cosa, no existe ningún trabajo que lo analice detalladamente. Este artículo, trata de poner de relieve la relación de la carta de 1500 con las obras mallorquinas, al menos en lo que a la representación de la leyenda del encierro de Gog y Magog se refiere, a la espera de la publicación de otro en el que se aborda este tema con mayor detenimiento, que actualmente estoy redactando.
}

$A E A$, LXXVIII, 2005, 311, pp. 263 a 276 

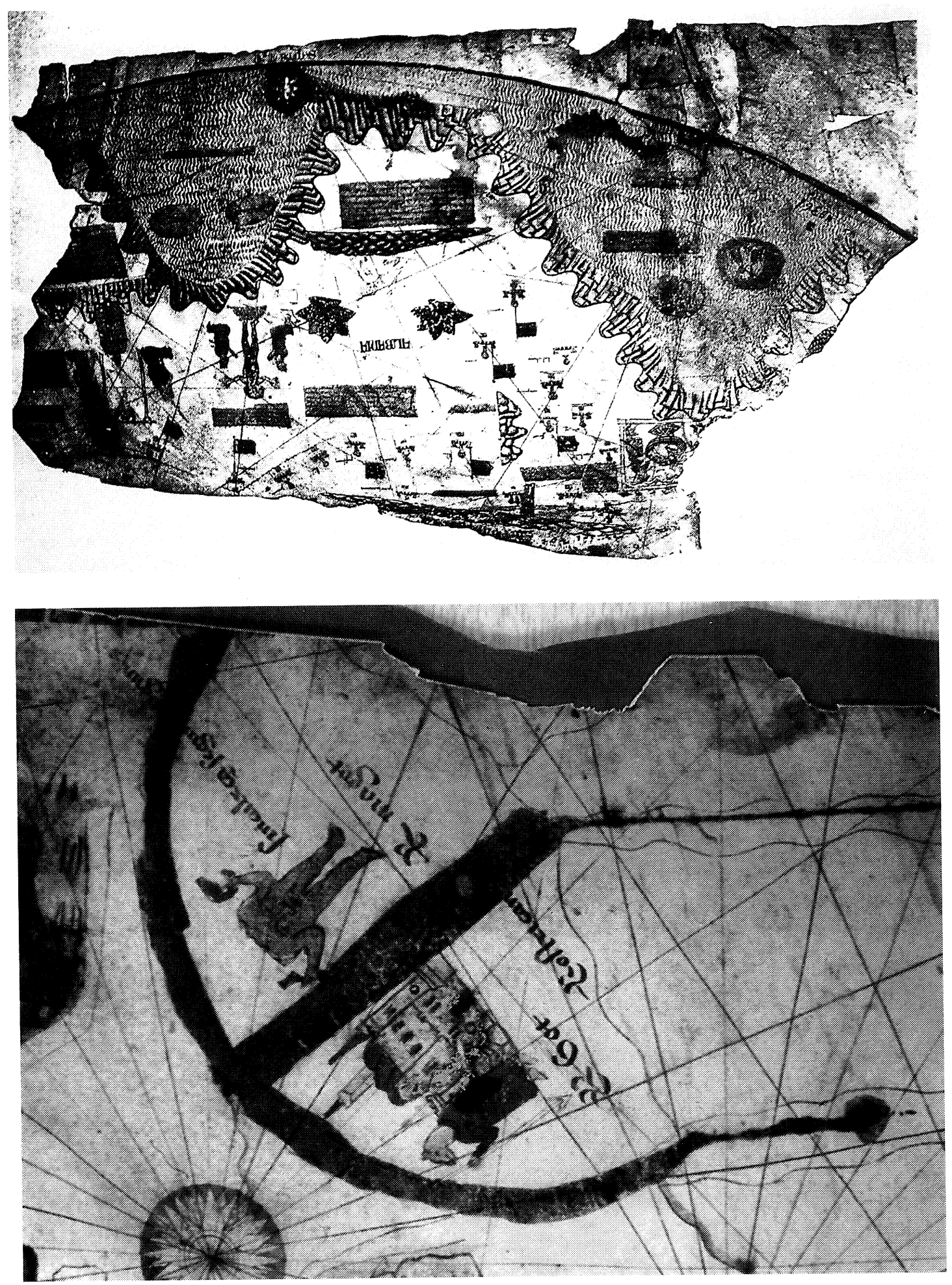

Fig. 7. Montes del Caspio (fragmento). Carta Mallorquina de Estambul, Topkapi Saray Kutuphane, Estambul, H. 1828. Reproducido de J. R. Enterline, Erikson, Esquimos and Columbus. Medieval European Knowledge of America, Baltimore and London, The Johns Hopkins University Press, 2002, fig. 26. La fotografía del mapa está orientada al Norte.

Fig. 8. Gog y Magog. Carta de Juan de la Cosa, Museo Naval (Madrid). Reproducido del Facsímil del Museo Naval (Madrid), A-10282. La fotografía del mapa está orientada al Norte. 
micírculo cercando un espacio, a su vez dividido en dos partes a través de un tramo de cordillera. Tras estos montes están encerrados «R. Got» $\mathrm{y}$ «R. Magot». Desde el punto de vista filológico y paleográfico hay que destacar que la abreviatura de «R» debe de aludir a «Rey». Por otro lado, la variación de Gog a Got y Magog a Magot debe estar vinculado a la asimilación de estos pueblos invasores con los Godos ${ }^{52}$. En el espacio meridional aparece la representación de «R. Got», el cual, siguiendo la leyenda que lo acompaña que afirma «Rostrican», está ilustrado como un monstruo con cabeza de perro, y aparece armado con lanza y escudo. Al fondo se encuentra una construcción arquitectónica. En el espacio ubicado al Norte se encuentra «R. Magot», representado como un Blemmya, monstruo sin cabeza con el rostro sobre el pecho, tal como indica la leyenda que le acompaña: «Sin cabeça según algun[os]». Aparece exhibiendo unos brotes dorados en sus manos. F. Silió Cervera vinculó a Magog con el Anticristo y destacó que portara los brotes dorados del mismo modo que una figura que aparece en la portada de la edición en castellano del Itinerarium de Jean de Mandeville editada en Valencia en $1521^{53}$. Aunque esta edición es unas décadas posterior a la Carta de Juan de la Cosa, quizá esta representación de la obra de Mandeville derivara de una tradición iconográfica anterior, y al menos, en el terreno cartográfico, el punto de arranque de esta imagen pudiera quizá encontrarse en el Atlas Catalán, en el que el Anticristo porta unas ramas con frutos dorados.

En la Carta de Juan de la Cosa, a diferencia de lo que ocurre en el Atlas Catalán, no aparece la diferenciación entre Gog y Magog y el Anticristo. No obstante, Magog ha heredado uno de los atributos distintivos del Anticristo de la carta mallorquina.

En resumen, se podría afirmar que en la Edad Media, el encierro de Gog y Magog va a ocupar un lugar destacado dentro de las concepciones geográficas, siendo por ello representado en la cartografía de este momento. Por lo que a esto se refiere, la carta de Cresques Abraham es un claro ejemplo de la asimilación de la figura del Anticristo dentro de dicha leyenda. En dicha representación se ilustra al Anticristo como un falso profeta realizando milagros, en concreto el hacer florecer unas ramas secas. La representación de Gog y Magog, y el Anticristo tras los montes del Caspio va a perdurar dentro de otras cartas náuticas de la Escuela Cartográfica Mallorquina, relacionadas con el Atlas Catalán, bien por pertenecer al mismo taller o por estar incluidas dentro de la misma corriente artística. Esta representación pasa de las cartas mallorquinas a la Escuela Cartográfica de Sevilla. A partir de este momento, el siguiente paso en la evolución de esta imagen habría consistido en la asimilación de Magog con el Anticristo y consecuentemente con los atributos del mismo, las ramas florecidas, tal como se pone de manifiesto en la Carta de Juan de la Cosa.

\footnotetext{
${ }^{52}$ Anderson, A. R., Op. cit., (1932), pp. 9-12.

${ }^{53}$ Silió Cervera, F., La Carta de Juan de la Cosa (1500). Análisis cartográfico, Santander, Fundación Marcelino Botín, 1995 , p. 126.
} 